\section{Von Ärzten und Piloten}

Die langfristige Akkumulation von Hiobsbotschaften kann tatsächlich zu einem Crash führen, der einen ganzen Wirtschaftszweig erschüttert. Das war zweifellos das einschneidende Erlebnis der vergangenen Monate in unserem Land. Als Konsequenz daraus ist uns spätestens seither auch bewusst, dass neben dem Gesundheitswesen offenbar auch der Luftverkehr ein schützenswertes öffentliches Gut darstellt, dessen öffentliche Zuwendung andere Bedürftige wohl mit Liebesentzug zu erdulden haben.

Früher wurden die Berufe von Ärzten und Piloten gerne miteinander verglichen. Beide umgibt der Nimbus, in existentiellen Grenzbereichen tätig zu sein. In ihrer täglichen Arbeit gelingt es ihnen, offenbare Naturgesetze wie die Erfahrungen von Krankheit und Schmerz oder die Gesetze der Schwerkraft zumindest teilweise zu überwinden. Beide verdanken ihren Erfolg sowohl der naturwissenschaftlichen Erkenntnis als auch der Beherrschung einer sich rasch entwickelnden Technik. Beide haben in den vergangenen Jahrzehnten von und in ihrer Rolle nicht allzu schlecht gelebt und beide finden sich zurzeit mit Verwunderung im Rampenlicht der öffentlichen Kritik wieder.

Was ist mit den Piloten passiert? "Fliegen», so hörte man staunend von nüchternen Ökonomen, biete zwar ein «attraktives emotionales Pro- dukterlebnis", doch Fliegen sei längst nicht mehr das Kerngeschäft einer Airline. Fluggesellschaften sind in erster Linie Logistikunternehmen und Streckennetzkomplettierer geworden, verkauft wird Mobilität, da ist das "Fliegen" nur noch ein Teilschritt in der Wertschöpfungskette. Einst von passionierten Piloten gegründet, haben längst andere das Steuerruder der Gesellschaften übernommen und sie nach gleichen Mechanismen und Wertmassstäben umstrukturiert wie die Bierdosen-oder die Zementindustrie. Die Piloten, an ihrer zentralen Schaltstelle unentbehrlich, wurden als Kompensation für ihre Marginalisierung in betrieblichen Entscheidungsprozessen, mit guter Bezahlung und reichlichen Privilegien bei Laune gehalten. Ansonsten waren sie Dienstleister, man könnte fast sagen Leistungserbringer, und auch über den Wolken immer noch fest eingebettet in die nebulösen Ziele einer undurchsichtigen Konzernstrategie.

Die Konfrontation mit der Realität scheint für viele Piloten hart und schmerzhaft zu sein. Doch ist es nicht auch tröstlich, dass die wesentlichen Impulse zur Erneuerung im Flugverkehr heute offenbar wieder von Personen ausgehen, die selber einmal als Flugkapitäne am Steuerknüppel sassen, von Personen also, die das Kerngeschäft "Fliegen» kennen?

Im Gesundheitswesen und insbesondere in den Spitälern ist natürlich alles ganz anders.

Ludwig T. Heuss Mitglied des Zentralvorstands FMH 